\title{
Psychometric Proprieties and Construct Validity of the Brother-Sister Questionnaire in a Sample of Portuguese Adolescents
}

\author{
Inês Carvalho Relva ${ }^{1,3}$ • Otília Monteiro Fernandes ${ }^{1}$ - Madalena Alarcão ${ }^{2,3}$. \\ Sandra Graham-Bermann ${ }^{4} \cdot$ Patrícia Lopes ${ }^{1}$
}

(C) Springer Science+Business Media New York 2016

\begin{abstract}
The Brother-Sister Questionnaire (BSQ; GrahamBermann and Cutler 1994) is an instrument designed to measure qualities of sibling relationships. Aim: In the present study the main objective was to examine the psychometric properties and validity construct of BSQ - Portuguese version. Data were collected among 197 adolescents. The Cronbach's alpha of the four domains ranged from .58 to .84 . The psychometric characteristics of BSQ Portuguese version were found to be adequate. The results confirm the multi-dimensional model composed of four factors proposed by the authors of this instrument, as well as their suitability to assess quality of Portuguese sibling relationships. The BSQ offers a reliable and valid measure to be used within Portuguese population.
\end{abstract}

Keywords BSQ $\cdot$ Reliability $\cdot$ Siblings $\cdot$ Confirmatory factor analysis

Relationships between siblings, according to some authors (e.g., Bank and Kahn 1997), are the longest relationships in our life. Sibling relationships, when compared with others relationships, offer unique opportunities for both learning about themselves and others (Dunn 2000), especially when they

Inês Carvalho Relva

irelva@utad.pt

1 Department of Education and Psychology, University of Trás-os-Montes e Alto Douro, Polo I, Quinta de Prados, 5000-801 Vila Real, Portugal

2 Faculty of Psychology and Sciences of Education, University of Coimbra, Coimbra, Portugal

3 Centre for Social Studies, University of Coimbra, Coimbra, Portugal

4 Department of Psychology, University of Michigan, Ann Arbor, MI, USA speak about their feelings (Dunn 2005), share knowledge, perceptions, attitudes and beliefs. Johnston and Freeman (1989) found that long-term relationships between siblings who are positive have a beneficial effect on young, and the reverse also happens. Moreover, sibling relationships appear to be associated with the development of an individual's social skills, cognitive skills and ability to cooperate with others (Noller 2005). Siblings are also extremely important since they may influence other relationships namely, parent-to-parent, parents-to-child, and extra-family relationships, such as peers and dating. Sibling relationships and their contribution to development can only be understood in the context of other family relationships (Hetherington 1994), since sibling relationships do not occur in isolation, but rather as a component of other dyadic subsystems that are interrelated (Criss and Shaw 2005).

However sibling relationships, like other relationships in the family, may be abusive and can contribute to dysfunctional development. Sibling violence has been identified as the most prevalent form of violence in the family (Straus et al. 1980), although researchers claim that it is underreported (Caspi 2012) and neglected in research studies (Krienert and Walsh 2011). In Portugal, although there are few studies conducted, the prevalence of sibling violence is very high both in adolescents (Lopes et al. 2015) and in university students (Relva et al. 2013b; Relva et al. 2014) and appears to be as prevalent as in other countries namely, the United Kingdom (Khan and Rogers 2015), and the United States (GrahamBermann and Cutler 1994; Hardy et al. 2010). Thus, sibling violence appears to be a universal phenomenon. The consequences are also diverse and can be seen in both short and long term, such as greater depression and anxiety (Duncan 1999), substance abuse and eating disorders (Wiehe 1997), alcohol abuse (Button and Gealt 2010), problems in different relationships such as with peers (Criss and Shaw 2005), and in dating (Simonelli et al. 2002). 
Because siblings are so relevant to children's development, it is important for clinicians to have measures that help to distinguished between nonabusive and abusive sibling dyads. According to Graham-Bermann (2004) there is a lack of studies concerning this topic. Therefore, Graham-Bermann and Cutler (1994) found, after reviewing the literature, that "most meaningful family relationships have been described in terms of four qualities: 1) sufficient generational and individual boundaries, 2) some similarities as well as differences between family members, 3) low levels of coercion within the family, and 4) high levels of empathy" (cf. Graham-Bermann and Cutler 1994). The authors then hypothesized that these characteristics would adequately describe childhood sibling relationships as well. In this way the four constructs, boundary maintenance, differentiation of the self from other people, power, and ability to empathize have been used to describe sibling relationship that are healthy, supportive, and balanced relationships. However, it is unclear whether these same constructs can be useful in characterizing the relationships of siblings living in Portugal.

\section{Aims}

The main objective of the present study was the adaptation of the Brother-Sister Questionnaire (BSQ; Graham-Bermann and Cutler 1994) for use with a Portuguese sample. By translating and then back translating the BSQ items, a Portuguese version of the measure was created. The psychometric proprieties were tested to ascertain whether similar constructs as those found with samples of young adults in the United States can be reliably obtained with a sample of Portuguese adolescents. Further the comparison of the BSQ constructs with other measures of sibling conflict was used to add construct validity. Finally we used confirmatory factor analysis (CFA), which according with some authors "is a more thorough and strident way of testing theoretical models than principal factor analysis" (Derkman et al. 2010; p. 282) (Fig. 1).

Concluding, the current study intends to examine the psychometric properties and validity construct of BSQ, and some hypothesis were addressed (a) it was hypothesized that the four constructs of the original BSQ will be replicated in this Portuguese sample. In accord with prior research, (b) we hypothesized that the BSQ domains will be significantly correlated with a measure of dyadic sibling conflict (the CTS2-SP); (c) we expected that BSQ Empathy, Boundary Maintenance and Similarity would be negatively correlated with CTS2-SP scales and finally (d) BSQ coercion would be positively correlated with CTS2-SP scales concerning Psychological Aggression, Physical Assault and Injury.

\section{Methodology}

\section{Sample}

The sample consisted of 197 subjects, aged 11 to 16 years $(M=13.51, S D=1.08)$, the majority were female $(66 \%)$ and of Portuguese nationality (92.4\%). With regard to education, the participants attended the 3 rd cycle of basic education, $93(47.2 \%)$ were in the 7 th grade, $76(38.6 \%)$ studied in 8 th grade and $28(14.2 \%)$ attended the 9 th grade. Regarding the number of siblings, the majority ( $69 \%$ ) had only one, while $24.4 \%$ had two, $3.6 \%$ had three, $2 \%$ had four and $1 \%$ had five siblings. Regarding the age of parental figures, father age ranged between 34 and 66 years $(M=44.86, S D=5.87)$ and the mother's age ranged between 30 and 59 years $(M=42.44$, $S D=5.80$ ). The parents' marital status was $89.8 \%$ married or in a committed union.

\section{Procedures}

After obtaining institutional approval and commitment, anonymous questionnaires were self-administered in classes of different schools in the north of Portugal. However, first the parents read an informed consent document that they signed to give their own approval for their child to participate in the study. Its completion was voluntary and without recourse to any kind of external encouragement. The administration schedule was agreed to by teachers responsible for the classes, usually happening before or after classes. Some research objectives were explained to participants before asking them to complete the protocol, namely that the study aim was to validate a psychometric measure. The questionnaire was administered by the teacher after receiving instruction in its administration by the researcher.

\section{Measures}

Demographics Questionnaire Demographic information was obtained from each participant. These questions included age, gender, parents' ages and parent's marital status, number, age and gender of siblings.

The Brother-Sister Questionnaire (BSQ; Graham-Bermann and Cutler 1994) is a self- report instrument with 35 items used to assess elements of sibling relationships, namely, the degree of differentiation, boundary maintenance, empathy, and the relative balance of power and control in the relationship (Graham-Bermann and Cutler 1994). Each participant was asked to complete this questionnaire in reference to the relationships between him or herself and the sibling with whom he or she had the most conflict while growing up. A Likert scale is used by participants who were asked to rate how much each item describes their relationship with their 
Fig. 1 Confirmatory factorial analysis of BSQ

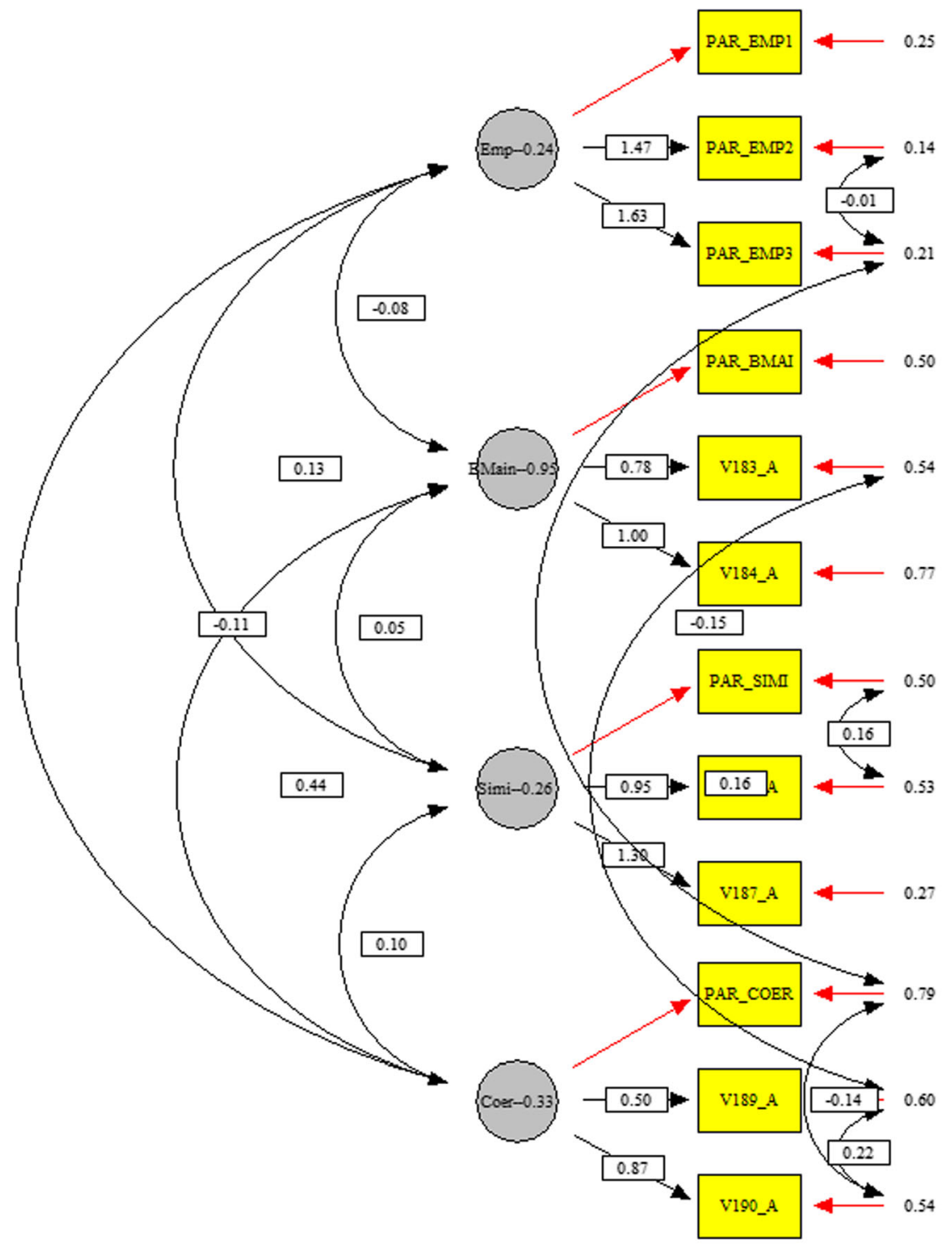

designated sibling, with ratings from One (Not at all true), Two (Not very true), Three (Sometimes true), Four (Often true), to Five (Very much true). The measure was proven to be valid and reliable in a study of 18-19 year old first year college students (Graham-Bermann and Cutler 1994) and replicated in a second study (Graham-Bermann et al. 1994). Internal consistence in the original study was reported: Empathy $(\alpha=.92)$, Boundary Maintenance $(\alpha=.85)$, Similarity $(\alpha=.73)$, and Coercion $(\alpha=.69)$ (GrahamBermann et al. 1994).

Empathy This scale assesses the extent to which the siblings care about one another, would feel bad if the other felt bad, would share secrets, feel close, spend time together, and care for one another. The scale consists of 14 items that reflect the degree to which the siblings are emotionally connected and tuned in to what the other person is experiencing. Higher scores indicate greater empathy and caring in the relationship.

Boundary Maintenance The scale assesses the degree to which siblings are able to maintain interpersonal boundaries. This scale has six items that reflect the extent to which the two siblings are successful in establishing and respecting firm and reasonable boundaries between them. These parameters include boundaries around both physical property and feeling that one's wishes are understood; in other words respecting the other person's physical and psychological space. It is assumed that during childhood most siblings squabble over boundaries 
and defining territory vis-a-vis one another. Lower scores reflect a failure to maintain boundaries, perhaps those which are easily or repeatedly violated, while higher scores reflect less concern with and greater success in having one's boundaries respected.

Similarity This scale examines ways in which the two siblings have common interests and experiences. Nine items include the degree to which the siblings have shared friends, and like the same sports, hobbies, and school subjects. This scale also assesses the extent to which they have the same experience within the family in terms of doing the same chores and getting in approximately the same amount of trouble. Higher scores indicate greater similarity in the relationship. Low scores suggest that the siblings are strongly differentiated or de-identified and see themselves as having little in common.

Coercion This scale assesses elements of power and control of one sibling over the other with six items. It includes questions about exploitative behavior, such as having been introduced to deviant or "bad behavior" by a sibling and feeling used by the sibling. The scale also taps rejection by a sibling and efforts to isolate the sibling by keeping friends away. When the subject indicates being dominated and controlled by a sibling, the coercion score will be higher.

The Revised Conflict Tactics Scales (CTS2-SP Sibling Version; Straus et al. 1996). The CTS2-SP consists of 78 items grouped into five scales: (1) Negotiation (6 items), (2) Psychological Aggression (8 items), (3) Physical Assault (12 items), (4) Sexual Coercion (7 items) and (5) Injury (6 items); however given the objective of the present study, we have excluded the negotiation scale. The CTS2-SP questions were presented in relationship pairs (experiences of received and expressed psychological and physical aggression). The scale of response reflects the frequency of each behavior over a period of time (0) this has never happened, (1) once a year, (2) twice a year, (3) 3-5 times a year, (4) 6-10 times a year, (5) 11-20 times a year, (6) more than 20 times a year, (7) not that year, but it happened. When there was more than one sibling involved, participants were instructed to answer concerning the same sibling as for the BSQ. The CTS2-SP was adapted by Relva et al. (2013a) and this version has adequate psychometric proprieties. Reliabilities of CTS2-SP range from .65 to .81 for the perpetration scales and ranging from .66 to .84 to victimization scales.

\section{Statistical Procedures}

The study of psychometric proprieties and construct validity of the Brother-Sister Questionnaire were determined with Cronbach alphas using SPSS and with Confirmatory Factor Analysis (CFA) of the first order (method of Maximum
Likelihood) using the EQS 6.1 program. For Windows (Bentler 2006). The methodology used was a model assuming no correlation between the errors and observing the Lagrange test indicators for the correlation between errors (Brown, 2006).

For carrying out the CFA, plots were built of random items for Brother-Sister Questionnaire scales. The use of structural equation modeling (SEM) to estimate reliability has been used increasingly because it is informative (Yang and Green 2011) and permits us to confirm if our results are according with the model proposed by the original authors of the instrument. The procedures of random construction of items, observing the normal distribution of the items and descriptive data were performed using the statistical program SPSS for Windows (version 22). In order to determine whether these is a significant association between the BSQ scales and CTS2-SP scales Pearson Correlations were performed.

\section{Results}

\section{Internal Consistency}

Results of the reliability analyses for the four factors of the BSQ were as follows: Empathy $(\alpha=.84)$, Boundary Maintenance $(\alpha=.81)$, Similarity $(\alpha=.72)$, and Coercion $(\alpha=.58)$.

Our results are similar with the authors of the instrument, however the reliability for the coercion domain is lower $(\alpha=.58)$. Concerning the CFA, the value of adjustments

Table 1 Socio-Demographic Characteristics $(N=197)$

\begin{tabular}{lll}
\hline Socio-Demographic Characteristics & & \\
\hline Gender & Male & $34 \%$ \\
& Female & $66 \%$ \\
Age Mean (SD) 13.51 (1.08) & & \\
Portuguese nationality & & $92.4 \%$ \\
Level of education & 7 th Grade & $47.2 \%$ \\
& 8th Grade & $38.6 \%$ \\
Number of brothers/sisters & 9 th Grade & $14.2 \%$ \\
& 1 & $69 \%$ \\
& 2 & $24.4 \%$ \\
& 3 & $3.6 \%$ \\
Parents' age & 4 & $2 \%$ \\
& $5=»$ & $1 \%$ \\
& Father $(34-66$ years) & \\
Parents' marital status & $M=44.86 ; S D=5.87$ \\
or in a committed union & Mother (30-59 years) \\
\hline & $M=42.44 ; S D=5.80$ \\
\hline
\end{tabular}


confirms the original model $\chi^{2}(37)=87.920 ; p=.000$; Ratio $=2.376 ; \mathrm{CFI}=.94 ; \mathrm{RMR}=.07$ e $\mathrm{RMSEA}=.08$.

Concerning the Revised Conflict Tactics Scales SP Cronbach alpha of total scale was $\alpha=.96$. Regarding the subscales, the results for perpetration by the participant were: .65 for Negotiation, .75 for Psychological Aggression, .90 for Physical Assault, and .87 for Injury. For victimization by the sibling the results were: .70 for Negotiation; .76 for
Psychological Aggression; .89 for Physical Assault; and .88 for Injury. Regarding confirmatory factor analysis for the CTS2-SP perpetration scale confirms the adjustment of values and $\chi^{2}(44)=126.220 ; p=.000 ;$ Ratio $=3.748 ; \mathrm{CFI}=.91$; $\mathrm{RMR}=.149$ e RMSEA $=.09$. The values for victimization scale were also adjusted $\chi^{2}(45)=116.509 ; p=.000$; Ratio $=2.589 ; \mathrm{CFI}=.92 ; \mathrm{RMR}=.14$ e RMSEA $=.09$ (Table 1).
Table 2 Brother-sister questionnaire: descriptive statistics of the items, item-to-total correlation, cronbach's alpha and cronbach's alpha if item deleted

\begin{tabular}{|c|c|c|c|c|}
\hline Scale Items & Mean(SD) & ITC $^{*}$ & $\alpha$ & $\alpha$ if item deleted \\
\hline Empathy & & & .84 & \\
\hline 2. We do a lot of arguing or fighting. & $2.89(1.17)$ & -.25 & & .87 \\
\hline 4. I would loan money to him or her. & $3.50(1.58)$ & .24 & & .85 \\
\hline 7. I care a lot about what he or she does. & $4.05(1.10)$ & .66 & & .82 \\
\hline 8. He or she cares a lot about what I do. & $3.62(1.21)$ & .67 & & .82 \\
\hline 14. When she or he feels happy, I do too. & $3.67(1.27)$ & .52 & & .83 \\
\hline 17. We spend a lot of time together. & $3.75(1.12)$ & .34 & & .84 \\
\hline 19. We are very close to each other. & $3.99(1.11)$ & .65 & & .82 \\
\hline 20. We usually get along very well. & $4.01(1.07)$ & .50 & & .83 \\
\hline 21. I would tell my biggest secret to her or him. & $3.17(1.47)$ & .58 & & .83 \\
\hline 22. He or she feels bad when I feel bad. & $3.07(1.23)$ & .59 & & .83 \\
\hline 28. We are good friends or buddies. & $3.97(1.10)$ & .59 & & .83 \\
\hline 29. I care a lot about what he or she thinks. & $3.45(1.19)$ & .71 & & .82 \\
\hline 30. He or she cares a lot about what I think. & $3.19(1.21)$ & .53 & & .83 \\
\hline 35. He or she takes care of me a lot. & $3.55(1.27)$ & .58 & & .83 \\
\hline Boundary Maintenance & & & .81 & \\
\hline 3. He or she always tries to copy me. & $2.19(1.49)$ & .65 & & .76 \\
\hline 16. He or she takes my things without asking. & $3.18(1.39)$ & .48 & & .80 \\
\hline 26. He or she always tries to do what I am doing. & $2.20(1.27)$ & .57 & & .78 \\
\hline 27. She or he always gets into my stuff. & $2.38(1.28)$ & .48 & & .80 \\
\hline 31. If I get something, he or she always wants it too. & $2.77(1.45)$ & .58 & & .78 \\
\hline 32. She or he always makes a mess of my things. & $2.47(1.47)$ & .68 & & .76 \\
\hline Similarity & & & .73 & \\
\hline 1. We are very much alike. & $3.32(1.08)$ & .27 & & .72 \\
\hline 6. We like the same sports and games. & $3.15(1.37)$ & .52 & & .68 \\
\hline 9. We have the same friends. & $2.29(1.37)$ & .45 & & 69 \\
\hline 10. We argue a lot about whose turn it is to do things. & $2.82(1.41)$ & .19 & & .75 \\
\hline 11. We are good at the same school subjects. & $2.41(1.23)$ & .51 & & .68 \\
\hline 12. We like to do the same things. & $2.73(1.14)$ & .56 & & .68 \\
\hline 13. We get in about the same amount of trouble. & $3.08(1.18)$ & .26 & & .73 \\
\hline 15. We like the same TV shows. & $3.37(1.16)$ & .45 & & .70 \\
\hline 18. We do about the same amount of chores. & $2.79(1.26)$ & .45 & & .70 \\
\hline Coercion & & & .58 & \\
\hline 5. I get to do things before my brother or sister. & $2.57(1.37)$ & .20 & & .60 \\
\hline 23. My brother or sister gets blamed more than me. & $2.61(1.43)$ & .21 & & .60 \\
\hline 24. I felt rejected by my brother or sister. & $1.73(1.11)$ & .36 & & .52 \\
\hline 25. He or she tries to keep me away from my friends. & $1.40(.91)$ & .41 & & .51 \\
\hline 33. He or she shows me how to do bad things. & $1.66(1.05)$ & .37 & & .52 \\
\hline 34. I feel used or taken advantage by him or her. & $1.58(1.04)$ & .49 & & .47 \\
\hline
\end{tabular}

*ITC $=$ Item-to-Total Correlation 


\section{Correlation between the BSQ and CTS2 - SP Domains}

Table 2 shows the correlation matrix between the domains of BSQ and CTS2-SP domains. Some components are significantly inter-correlated. Similarity was positively correlated with Empathy $(r=.44, p<.01)$. Coercion was positively correlated with Boundary Maintenance $(r=.51, p<.01)$ and negatively correlated with Empathy $(r=-.31, p<.01)$. Regarding CTS2-SP domains, Negotiation was positively correlated with Similarity $(r=.25, p<.01)$. Psychological Aggression was positively correlated with Boundary Maintenance $(r=.34, p<.01)$, Coercion $(r=.30, p<.001)$ and Negotiation $(r=.50, p<.01)$ and negatively correlated with Empathy $(r=-.16, p<.01)$. Physical Assault was positively correlated with Boundary Maintenance $(r=.31$, $p<.05)$, Coercion $(r=.30, p<.01)$, Negotiation $(r=.46$, $p<.01)$, and Injury $(r=.85, p<.01)$; and was negatively correlated with empathy $(r=-.22, p<.01)$. Finally, Injury was positively correlated with Boundary Maintenance $(r=.17$, $p<.05)$ Coercion $(r=.22, p<.05)$, Negotiation $(r=.46$, $p<.01)$, Psychological Aggression $(r=.77, p<.01)$ and Physical Assault $(r=.95, p<.01)$ was also negatively correlated with Empathy $(r=-.21, p<.01)$ (Table 3).

\section{Discussion}

Because the sibling relationship it is so important, we intended to improve the use of instruments that help professionals to evaluate that relationship. Therefore, in this study we sought to explore the psychometric proprieties of the BSQ in a sample of Portuguese adolescents and to test the theoretical model underlying this instrument. The results in the present sample show similar construct reliabilities to those find by the authors of the scale. However the reliability for the coercion domain was lower $(\alpha=.58)$. Straus (2007) argues when the Cronbach alpha is low this can be explained by the absent or the low frequencies of some items. Therefore, the first hypothesis was confirmed, this is, the four constructs of the original BSQ were replicated in our sample.
The moderate correlations between similarity and empathy suggest that siblings who see themselves as similar with the other sibling had more positive relationships with them (Graham-Bermann, 1991). Also in a recently study, with a sample that ranged in age from 7 to 14 years, Lam et al. (2012) found that warmth and less sibling conflict were associated with more empathy. The high correlation between coercion and boundary maintenance was not a finding in the original study, yet this can be explained perhaps by the normalization of some behaviors that occur in sibling relationships that seems most of the time as normal (Kettrey and Emery 2006; Phillips et al. 2009). By this way, although respecting sibling boundaries, aggressors use coercion as an instrument to get what they want.

Concerning the second hypothesis, we hypothesized that BSQ dimensions and the CTS2-SP dimensions would be significantly correlated. The results confirm this hypothesis and also demonstrate construct validity (cf. Westen and Rosenthal 2003). It was also expected that Empathy, Boundary Maintenance and Similarity scales would be negatively related with Psychological Aggression, Physical Assault and Injury. Analyzing the correlations, we can see that Empathy it is negatively correlated with that scales. These results are according with results from other studies, namely from the original one. Derkman et al. (2010) found in a sample with 428 adolescents aged 13 to 16 that relationship warmth/ closeness was negatively correlated with externalized behaviors. Lam et al. (2012) also found that high levels of empathy were associated with closer relationships with their siblings.

Boundary Maintenance was correlated positively with all negative scales from CTS2-SP. This result wasn't unexpected, because high levels of boundary maintenance usually appear correlated with low levels of coercion (Graham-Bermann and Cutler 1994). However, this result is consistent with previously results, when the coercion scale was correlated with Boundary Maintenance. As already mentioned, although there are negatives behaviors and although siblings know the limits of each other, they may use negative ways of solving problems such as using psychological or physical aggression. Most of the behaviors that occur between siblings are seen as "kid's
Table 3 Correlation between BSQ and CTS2-SP Domains

\begin{tabular}{lllllllll}
\hline BSQ/CTS2-SP & 1 & 2 & 3 & 4 & 5 & 6 & 7 & 8 \\
\hline 1- Empathy & - & & & & & & & \\
2 - Boundary Maintenance & -.135 & - & & & & & & \\
3 - Similarity & $.437^{* *}$ & .035 & - & & & & & \\
4 - Coercion & $-.306^{* *}$ & $.505^{* *}$ & .127 & - & & & \\
5 - Negotiation & .092 & .106 & $.247^{*}$ & .138 & - & & \\
6 - Psychological aggression & $-.234^{* *}$ & $.335^{* *}$ & -.109 & $.297^{* *}$ & $.499^{* *}$ & - & \\
7 - Physical assault & $-.222^{* *}$ & $.314^{* *}$ & .002 & $.301^{* *}$ & $.457^{* *}$ & $.851^{* *}$ & - \\
8 - Injury & $-.205^{* *}$ & $.169^{*}$ & .017 & $.222^{*}$ & $.436^{* *}$ & $.769^{* *}$ & $.944^{* *}$ & - \\
\hline
\end{tabular}

$* * p<.01 ; * p<.05$ 
stuff" (Finkelhor et al. 2006) and that normalization contributes to its maintenance (Wiehe 1998). Another explanation lies with the ambivalence of sibling relationship, as described by some authors (Jenkins 1992). Contrary to what was expected, Similarity was not statistically significantly related to Psychological Aggression. However it was significantly correlated with Negotiation. This result is consistent with previously results where, according to Graham-Bermann et al. (1994), siblings who see themselves as similar tend to be more cooperative in their relationships. Also in a study with 186 undergraduate students Pawlowski et al. (2012) found that when siblings use the relational communication themes of immediacy, similarity, receptivity, composure, and equality, they tend to use integrative conflict strategies.

Some scales were not correlated, such as Similarity with Physical Assault and Injury. One explication for that may be that siblings can vary in the way they cope with the conflict they experience in their relationships (Furman and Buhrmester 1985). Finally, Coercion was positively correlated with Psychological Aggression, Physical Assault and Injury as expected (cf. Derkman et al. 2010). This result was also consistent with Mackey et al. (2010) in which CTS2-SP Emotional and Physical Violence scales were positively related with Conflict in the sibling relationship. Additionally this result indicates that the relationship may be unbalanced (Graham-Bermann 2004).

\section{Strengths, Limitations and Suggestions for Future Studies}

As with most studies, this one also has limitations, namely, the use of a convenience sample and one that was limited to adolescents. Another limitation could be the use only one sibling's perspective in characterizing the sibling relationship. Future studies should analyze the psychometric properties of the BSQ in other samples (e. g. clinic populations, institutionalized siblings, siblings with disabilities, and also siblings living in new family's structures, such as adoption, or having gay parents. This expanded research would contribute significantly to having two perspectives and more diverse perspectives on the sibling relationship.

The Brother Sister Questionnaire will be made available to researchers and clinics as an instrument that can contribute to a deeper understanding of quality of sibling relationship, helping to distinguish healthy from conflict behaviors.

\section{References}

Bank, S. P., \& Kahn, M. D. (1997). The sibling bond (15th anniversary Ed.). New York: Basic Books. (Obra original publicada em 1982).

Bentler, P. M. (2006). EQS 6.1: Structural equations program manual. Encino, CA: Multivariate Software Inc.
Brown, T. A. (2006). Confirmatory factor analysis for applied research. New York: Guilford Press.

Button, D. M., \& Gealt, R. (2010). High risk behaviors among victims of sibling violence. Journal of Family Violence, 25(2), 131-140. doi:10.1007/s10896-009-9276-x.

Caspi, J. (2012). Sibling aggression: Assessment and treatment. New York: Springer.

Criss, M. M., \& Shaw, D. S. (2005). Sibling relationships as contexts for sibling training in low-income families. Journal of Family Psychology, 19(4), 592-600. doi:10.1037/0893-3200.19.4.592.

Derkman, M. M. S., Scholte, R. H. J., van der Veld, W. M., \& Engels, R. C. (2010). Factorial and Construct validity of the Sibling Relationship Questionnaire. European Journal of Psychological Assessment, 26(4), 277-283. doi:10.1027/1015-5759/a000037.

Duncan, R. D. (1999). Peer and sibling aggression: An investigation of intra and extra-familial bullying. Journal of Interpersonal Violence, 14(8), 871-886. doi:10.1177/088626099014008005.

Dunn, J. (2000). State of the art: Siblings. Psychiatry, 13(5), 244-249.

Dunn, J. (2005). Commentary: Siblings in their families. Journal of Family Psychology 19(4), 654-657.

Finkelhor, D., Turner, H., \& Ormrod, R. (2006). Kid's stuff: The nature and impact of peer and sibling violence on younger and older children. Child Abuse \& Neglect, 30(12), 1401-1421. doi:10.1016/j. chiabu.2006.06.006

Furman, W., \& Buhrmester, D. (1985). Children's perceptions of the qualities of sibling relationships. Child Development, 56, 448-461.

Graham-Bermann, S. A. (1991). Siblings in Dyads: Relationships among perceptions and behavior. The Journal of Genetic Psychology 152(2), 207-216.

Graham-Bermann, S. A. (2004). Assessing four domains of the childhood sibling relationship. In L. Nadelman, Research manual in child development, (2nd ed.)(pp. 403-414). London: Erlbaum Associates Publishers.

Graham-Bermann, S. A., \& Cutler, S. E. (1994). The Brother-Sister Questionnaire (BSQ): Psychometric assessment and discrimination of well-functioning from dysfunctional relationships. Journal of Family Psychology, 8(2), 224-238.

Graham-Bermann, S. A., Cutler, S. E., Litzenberger, B., \& Schwartz, W. (1994). Perceived conflict and violence in childhood sibling relationships and later emotional adjustments. Journal of Family Psychology, 8(1), 85-97.

Hardy, M. S., Beers, B., Burgess, C., \& Taylor, A. (2010). Personal experience and perceived acceptability of sibling aggression. Journal of Family Violence, 25(1), 65-71. doi:10.1007/s10896009-9270-3.

Hetherington, E. M. (1994). Siblings, family relationships, and child development: Introduction. Journal of Family Psychology, 8(3), 251253. doi:10.1037/0893-3200.8.3.251.

Jenkins, J. (1992). Sibling relationships in disharmonious homes: Potential difficulties and protective effects. In F. Boer \& J. Dunn (Eds.), Children's sibling relationships: Developmental and clinical issues (pp. 125-138). Hillsdale, NJ: Lawrence Erlbaum Associates, Inc.

Johnston, C., \& Freeman, W. (1989). Parent training interventions for sibling conflict. In M. James (Ed.), Handbook of parent training: Parents as co-therapists for children's behavior problems (2nd ed., pp. 153-176). New York: Wiley.

Kettrey, H. H., \& Emery, B. C. (2006). The discourse of sibling violence. Journal of Family Violence, 21(6), 407-416. doi:10.1007/s10896006-9036-0.

Khan, R., \& Rogers, P. (2015). The normalization of sibling violence: Does gender and personal experience of violence influence perceptions of physical assault against siblings? Journal of Interpersonal Violence, 30(3), 437-458. doi:10.1177/0886260514535095.

Krienert, J. L., \& Walsh, J. A. (2011). My brother's keeper: A contemporary examination of reported sibling violence using national level 
data, 2000-2005. Journal of Family Violence, 6(5), 331-342. doi:10.1007/s10896-011-9367-3.

Lam, C., Solmeyer, A., \& McHale, S. (2012). Sibling relationships and empathy across the transition to adolescence. Journal of Youth and Adolescence, 41(12), 1657-1670. doi:10.1007/s10964 012-9781-8.

Lopes, P. P., Fernandes, O. M., \& Relva, I. C. (Submitted, 2015). Sibling violence among Portuguese adolescents.

Mackey, A. M., Fromuth, M. E., \& Kelly, D. B. (2010). The association of sibling relationship and abuse with later psychological adjustment. Journal of Interpersonal Violence, 25, 955-968. doi:10.1177 10886260509340545.

Noller, P. (2005). Sibling relationships in adolescence: Learning and growing together. Personal Relationships, 12(1), 1-22. doi:10.1111/j.1350-4126.2005.00099.x.

Pawlowski, D., Myers, S., \& Rocca, K. (2012). Relational messages in conflict situations among siblings. Communication Research Reports, 17(3), 271-277.

Phillips, D., Phillips, K. H., Grupp, K., \& Trigg, L. (2009). Sibling violence silenced: Rivalry, competition, wrestling, playing, roughhousing, benign. Advances in Nursing Science, 32(2), 1-16.

Relva, I., Fernandes, O. M., \& Costa, R. (2013a). Psychometric Properties of Revised Conflict Tactics Scales: Portuguese Sibling Version (CTS2-SP). Journal of Family Violence, 28(6), 577-585. doi:10.1007/s10896-013-9530-08.

Relva, I. C., Fernandes, O. M., \& Mota, C. P. (2013b). An exploration of sibling violence predictors. Journal of Aggression, Conflict and Peace Research, 5(1), 47-61. doi:10.1108/17596591311290740.
Relva, I. C., Fernandes, O. M., Alarcão, M., \& Martins, A. (2014). Estudo exploratório da violência entre irmãos em Portugal. Psicologia: Reflexão e Crítica, 27(2), 398-408. doi:10.1590/16787153.201427221.

Simonelli, C. J., Mullis, T., Elliot, A. N., \& Pierce, T. W. (2002). Abuse by siblings and subsequent experiences of violence within the dating relationship. Journal of Interpersonal Violence, 17(2), 103-121. doi:10.1177/0886260502017002001.

Straus, M. A. (2007). Conflict Tactics Scales. In N. A. Jackson (Ed.), Encyclopedia of domestic violence (pp. 190-197). New York: Routledge, Taylor \& Francis Group.

Straus, M. A., Gelles, R. J., \& Steinmetz, S. K. (1980). Behind closed doors: Violence in the American family. Garden City: Anchor Books.

Straus, M. A., Hamby, S. L., Boney-McCoy, S., \& Sugarman, D. B. (1996). The Revised Conflict Tactics Scales (CTS2): Development and preliminary psychometric data. Journal of Family Issues, 17, 283-316. doi:10.1177/019251396017003001.

Westen, D., \& Rosenthal, R. (2003). Quantifying construct validity: Two simple measures. Journal of Personality and Social Psychology, 84(3), 608-618. doi:10.1037/0022-3514.84.3.608

Wiehe, V. R. (1997). Sibling abuse: Hidden physical, emotional, and sexual trauma (2nd ed.). California: Sage Publications.

Wiehe, V. R. (1998). Sibling violence. In V. R. Wiehe (Ed.), Understanding family violence: Treating and preventing partner, child, sibling, and elder abuse (pp. 167-217). Kentucky: Sage Publications.

Yang, Y., \& Green, S. B. (2011). Coefficient alpha: A reliability coefficient for the twenty-first century? Journal of Psychoeducational Assessment, 29(4), 377-392. 